\title{
PERFORMATIZAÇÕES QUEER NA EDUCAÇÃO FÍSICA ESCOLAR
}

\author{
QUEER PERFORMATIZATIONS IN SCHOOL PHYSICAL EDUCATION
}

PERFORMATIZACIONES QUEER EN LA EDUCACIÓN FÍSICA ESCOLAR

Rafael Marques Garcia*, Leandro Teofilo de Brito**

\begin{abstract}
Palavras chave: Identidade de gênero.

Minorias sexuais e de gênero. Educação Física.

Resumo: Objetivamos problematizar como se constituíam as relações de gênero e sexualidades nas aulas de Educação Física de uma escola municipal do Rio de Janeiro, com destaque para relatos da participação de um menino estudante que não se enquadrava nas normas binárias de gênero. A metodologia utilizada foi de caráter descritivo e qualitativo, através de observações participantes analisadas pela técnica de Análise de Conteúdo. Como base teórica, pautamo-nos nos estudos queer, encontrando manifestações desviantes dos padrões clássicos esperados para meninos e sua(s) masculinidade(s), sustentando estranhamentos, não pertencimento e não aceitação da performance fora da norma, fatos desconsiderados e não problematizados pelo docente responsável.
\end{abstract}

\section{Keywords:}

Gender identity.

Sexual and gender minorities.

Physical Education.

Palabras clave: Identidad de género. Minorías sexuales y de género. Educación Física.

Abstract: We discuss how gender relations and sexualities were established in Physical Education classes at a municipal school in Rio de Janeiro, with emphasis on reports about participation by a male student who did not fit into binary gender norms. The methodology used was descriptive and qualitative, using participant observations and applying content analysis. Our theoretical framework was queer studies, finding deviant manifestations towards expected traditional patterns for boys and their masculinity(ies), sustaining estrangement, not belonging non-acceptance of out-of-norm performance - facts that were not considered and not discussed by the teacher in charge.

Resumen: Objetivamos problematizar cómo se constituían las relaciones de género y sexualidades en las clases de Educación Física de una escuela municipal de Río de Janeiro, con destaque para relatos de la participación de un niño estudiante que no se enmarcaba en las normas binarias de género. La metodología utilizada fue de carácter descriptivo y cualitativo, a través de observaciones participantes analizadas por la técnica de análisis de contenido. Como base teórica, nos guiamos por los estudios queer, encontrando manifestaciones desviantes de los patrones clásicos esperados para niños y su(s) masculinidad(es), presentando extrañamiento, no pertenencia y no aceptación de la performance fuera de la norma, hechos desconsiderados y no problematizados por el docente responsable.
* Universidade Federal do Rio de Janeiro. Rio de Janeiro, RJ, Brasil. E-mail: rafa.mgarcia@ hotmail.com

** Colégio Pedro II. Rio de Janeiro, RJ, Brasil. E-mail: teofilo.leandro@gmail.com

Recebido em: 01/05/2018 Aprovado em: 11/12/2018

DOI https://doi.org/10.22456/1982-8918.82502 (c) (i) () Licence 


\section{INTRODUÇÃOO}

$\mathrm{Na}$ contemporaneidade, questões de gênero e sexualidade estão presentes cotidianamente nas escolas, viabilizadas conforme a visão biologicista e que mantém a congruência entre sexo/gênero/sexualidade/desejo (LOURO, 2013). As tentativas de debater novos horizontes e/ou possibilidades neste arranjo enfrentam forte censura do pensamento conservador que, como forma de demérito à militância feminista e LGBT, assim como aos estudos e pesquisas sobre gênero e sexualidade, nomeiam tais esforços como "ideologia de gênero".

Apoiando-se por este pensamento, assembleias e câmaras legislativas em diversas regiões do país aprovaram a retirada dos termos "gênero", "relações de gênero", "sexualidade" e "orientação sexual" de seus planos municipais e estaduais de educação, mantendo apenas menções genéricas e superficiais às discussões sobre preconceito e discriminação no ambiente escolar. O mesmo ocorreu, recentemente, com a Base Nacional Comum Curricular (BNCC), que veta por completo a palavra gênero, assim como também já havia ocorrido com o Plano Nacional de Educação (PNE) em 2014 (BRITO; SANTOS, 2018).

Deste modo, é através do espaço escolar que corpos são generificados e conduzidos apenas por modelações biomédicas, conforme a aparência do sexo anatômico, além de configurar instrumentos classificadores e hierarquizadores de meninos e meninas (MARIANO; ALTMANN, 2016).

Neste processo, o aprender e o educar se afloram de maneira díspar entre meninos e meninas. $O$ que se espera de cada um(a) deles(as)? Até que ponto determinadas ações desses pares permeiam a fronteira, ou ainda ameaçam transitar pelas territorialidades de gênero e sexualidades?

Conforme os estudos do historiador Philippe Ariès, a infância é reconhecida como uma categoria histórica e socialmente construída, em particular na cultura ocidental, contestando um sentido tido como natural, único e fixo, pois as concepções de criança e infância são transitórias e mutáveis nos diferentes contextos históricos (ARIĖS, 1981).

Considerando tais pontos, tornou-se naturalizado termos no espaço escolar a formação, já na infância, de masculinidades fortes, pois dos meninos esperam-se práticas de atividades violentas, que incidem na formação de jovens em uma trajetória linear e exponencial até a identidade absoluta de macho/homem (REIS; PARAÍSO, 2014). Nesses trâmites, surgem níveis de masculinidade, ou categorias de machos, sendo melhor ranqueado aquele que mais exacerba aspectos masculinizantes, tais como força, brutalidade, rebeldia e desobediência às normas escolares (ALTMANN, 2015). Já por outro lado, temos também a construção da outra polaridade desta lógica binária, que diz respeito à feminilidade. Através da incorporação de elementos graciosos, delicados, dedicação aos estudos, silêncio e submissão, as meninas são direcionadas para outro tipo de curva que, também seguindo uma lógica exponencial, visa educá-las para transformá-las em mulheres. Em suma, é possível identificar uma política pedagógica que incide na produção performativa de corpos sexuados, já na infância (REIS; PARAÍSO 2014).

A expressão produção performativa, supracitada, é subsidiada pela noção de performatividade de gênero, desenvolvida pela teórica feminista Judith Butler. Em suma, diz respeito aos atos, gestos e atuações que, repetidos com base nas normas regidas pela 
heterossexualidade reprodutora, buscam enquadrar os sujeitos arbitrariamente em modelos binários, coerentes e inteligíveis de sexo, gênero e desejo (BUTLER, 2015). Todavia, esse é um processo contingente e imprevisível, pois possibilita tanto a manutenção dessas normas como possibilidades de ressignificações e deslocamentos.

Dessa forma, podemos apontar as pedagogias escolares enquanto instrumentos heteronormatizadores ${ }^{1}$ e, portanto, excludentes (LOURO, 2010). Aquele(a) que não for conformado(a) por essas atribuições será hostilizado(a), sofrerá bullying, tornando-se chacota para os(as) demais e exemplo a não ser seguido(a), por conseguinte, "um corpo que não condiz com os padrões culturais de gênero é um corpo homossexual e/ou anormal" (REIS; PARAÍSO, 2014, p. 237). Daí irrompe a LGBTfobia², manifestação desencadeada para proteger o modelo heteronormativo através de condutas repressivas, ridicularizantes e opressoras das performatizações desviantes.

A criança é um artefato biopolítico que garante a normalização do adulto. A polícia de gênero vigia o berço dos seres que estão por nascer, para transformálos em crianças heterossexuais. A norma ronda os corpos meigos. Se você não é heterossexual, é a morte o que te espera. A polícia de gênero exige qualidades diferentes do menino e da menina. Dá forma aos corpos com o objetivo de desenhar órgãos sexuais complementares. Prepara a reprodução da norma, da escola até 0 congresso, transformando isso numa questão comercial (PRECIADO, 2013, p. 98).

Por conseguinte ao exposto, nas aulas de Educação Física, a articulação sexualidade/ gênero manifesta-se como protagonista durante a execução das tarefas, sendo rapidamente identificada ao desencadear respostas aos envolvidos através de inúmeras (in)exteriorizações, pois é neste componente curricular que o corpo se encontra mais exposto no processo de ensino aprendizagem (JACO; ALTMANN, 2017).

Para Goellner (2010), o uso do corpo promove nossa interação com o mundo através de um processo reconhecido por materialização discursiva. Corpo enquanto constructo social é perpassado por marcadores históricos e culturais que resultam em simbologias, normas e valores através de um processo inter-relacionado (GOELLNER, 2007; 2010).

Assim sendo, por reconhecer a escola como instância generificada e generificadora, a Educação Física Escolar legitima, também, corpos masculinos e femininos segundo uma ótica binária, heteronormativa e, sobretudo, regulada por mecanismos de poder (JACO; ALTMANN, 2017). Através de um discurso reiterativo, existe um forte esforço/reforço para estabelecer uma pedagogia corporal sobre meninos e meninas de modo que, caso não apresentem interesse por atividades tidas como mais próximas às atribuições essencialistas de gênero, terão, possivelmente, sua orientação sexual enquadrada como desviante, sofrendo mecanismos discriminatórios com o intuito de invisibilizá-los(as) e inferiorizá-lo(as) (DORNELLES; DAL'IGNA, 2015; PRADO; RIBEIRO, 2016).

É daí que emergem condutas LGBTfóbicas mais nitidamente, às quais se associam equivocadamente - performatizações de gênero dissidentes à norma à orientação homossexual. Não tratar do assunto em suas múltiplas esferas no espaço escolar, mantendo-se alheio(a) e indiferente, contribui para o silenciamento de processos de exclusão de identificações desviantes da heteronorma, sustentando o que Junqueira (2012) denomina como pedagogia

10 termo heteronormatividade diz respeito a ordem social que legitima a heterossexualidade como única forma possível de orientação sexual, assim como o enquadramento dos sujeitos dentro do binarismo masculino/feminino (WARNER, 1991).

2 Optamos pelo uso deste termo pois abrange de forma mais ampla as "fobias" relacionadas às identidades e expressões de gênero, tais como homofobia, lesbofobia e transfobia. 
do armário ${ }^{3}$, alavancada pela pedagogia do insulto ${ }^{4}$, que enfrenta concepções, práticas e estilos transgressores ou pervertidos conforme o olhar heteronormativo, consubstanciando e retroalimentando as condutas supracitadas.

A partir de tais pressupostos, temos como objetivo neste artigo problematizar como se constituíam as relações de gênero e sexualidades nas aulas de Educação Física Escolar de uma escola municipal localizada na cidade do Rio de Janeiro, com destaque para relatos da participação de um menino estudante que não se enquadrava nas normas binárias de gênero.

Para tanto, trazemos teorias queer como escopo teórico central neste artigo. Tais perspectivas surgem dos estudos pós-estruturalistas, com base em preceitos de Michael Foucault, Jacques Derrida e Judith Butler, objetivando problematizar a dinâmica do gênero, da sexualidade e do desejo na organização das relações sociais (MISKOLCl, 2009). Apropriandose do sentido de ofensa que o termo queer significa na língua inglesa, para inversão dessa significação como potência de luta política, as perspectivas queer problematizam a heterossexualidade como norma e a hierarquização dos pares binários masculino/feminino nas identificações de orientação sexual e gênero dos sujeitos.

Portanto, nossas análises se nortearão pela contestação do caráter fixo e estável das identidades sexuais e de gênero no espaço da Educação Física Escolar e como ela é tratada pelo corpo discente e docente do núcleo em questão.

\section{METODOLOGIA}

Este estudo é de caráter qualitativo e de tipo descritivo. O modelo qualitativo possibilita uma compreensão ampla acerca de fenômenos, permitindo sua interação dialógica com as diversas esferas sociais, possibilitando ainda as chances de continuidade e inúmeras possibilidades de análise (DEMO, 2012). Já o tipo descritivo busca transcrever processos (ou fenômenos) da maneira mais detalhada possível, incluindo peculiaridades e uma visão esmiuçada acerca dos eventos, contribuindo assim para uma análise bem apurada acerca do ponto estudado em questão (TRIVIÑOS, 2015).

Analisamos aqui relatos de experiência de um dos autores enquanto estudante da disciplina prática de ensino de uma universidade pública federal, no ano letivo de 2016, que era realizada em uma escola municipal localizada na Ilha do Governador, zona norte do Rio de Janeiro. Os sujeitos da pesquisa foram crianças estudantes do $1^{\circ}$ ano do ensino fundamental (13 meninos e 15 meninas, entre 6-7 anos), devidamente matriculadas e frequentando as atividades escolares, bem como o respectivo professor ${ }^{5}$ de EF da turma. Todos(as) os(as) participantes da pesquisa tiveram seu sigilo resguardado ${ }^{6}$.

30 termo remete às experiências do armário, isto é, àquilo que se invisibiliza e se revela, "Uma pedagogia que se traduz em uma pedagogia do armário, que se estende e produz efeitos sobre todos/as" (JUNQUEIRA, 2012, p. 69).

4 Compreendida como "As 'brincadeiras' heterossexistas e homofóbicas (não raro, acionadas como recurso didático) constituem-se poderosos mecanismos heterorreguladores de objetivação, silenciamento (de conteúdos curriculares, práticas e sujeitos), dominação simbólica, normalização, ajustamento, marginalização e exclusão" (JUNQUEIRA, 2012, p. 69).

5 Ao ser perguntando sobre como organizava e planejava o curso para a respectiva turma, o professor disse utilizar-se de diversos autores para formular seus princípios pedagógicos, entretanto não identificou nenhum deles. Disse também trabalhar com uma linha pedagógica mais esportivista, criando situações esportivas para despertar o interesse no aluno e favorecer o entendimento dos mais novos aos esportes em si. Para além disso, disse respeitar uma progressão pedagógica no que se refere aos materiais, trabalhando desde com bolas menores para maiores e vice-versa, dependendo do esporte que está sendo trabalhado, segundo ele, através de muitas atividades lúdicas. Não houve preocupação imediata ao que se refere às questões de gênero, sexualidades, heteronormatividade e pedagogias do armário e/ou exclusão, 0 que inclusive robustece nossos resultados e discussões. 
Considerando a perspectiva pós-estruturalista, que, conforme apresentamos, é base teórica central neste artigo, nos baseamos em autores(as) que pesquisam a categoria infância no campo de estudos de gênero e estão próximos a tal vertente, como Felipe (2009) e Couto Junior, Pocahy e Oswald (2018), para configurar os caminhos de nossa pesquisa de campo. Um dos princípios centrais dessa perspectiva é reconhecer que na pesquisa com crianças não alcançamos uma verdade natural e absoluta sobre elas, ou qualquer desvelar sobre a categoria infância, já que "[...] as falas das crianças devem ser examinadas como quaisquer outros textos culturais, isto é, visibilizando de que forma determinados mecanismos e práticas são mobilizados para produzir tais discursos" (FELIPE, 2009, p. 8).

Também requer atenção, nas pesquisas com crianças/infâncias em suas posições dissonantes às normas de gênero, um olhar crítico e reflexivo para as formas de insurgência, que contestam "[...] as noções sagradas e essencializadas de infância e do que é e pode uma criança" (COUTO JUNIOR; POCAHY; OSWALD, 2018, p. 61) denunciando assim, pelo texto acadêmico, as formas coercitivas de condução e governo da infância pelos sujeitos adultos.

O processo de coleta de dados ocorreu durante as aulas de Educação Física, uma vez por semana com duração de 1h40min cada, durante dez semanas, totalizando dez aulas e 16 horas e 40 minutos. Para este processo, utilizamos como instrumento a técnica de observação participante que, segundo Richardson (2008), é uma das principais e mais complexas técnicas utilizadas em pesquisa, principalmente pelo fato de, se mal realizada, influenciar os resultados obtidos. Observar de maneira participativa é estar presente, interagindo nas atividades sem, no entanto, direcionar ações ou quaisquer condutas que possam vir a interferir nos achados. Em função do objetivo, inclinamos nosso olhar para questões de gênero e sexualidades que se manifestassem em aula.

Para registrar os dados, utilizamos um diário de campo, sendo dividido pelos dias da semana e pelo número de aulas assistidas. Para tratá-los, reportamo-nos à leitura de Bardin (2016) e pela técnica de Análise de Conteúdo. Essa proposta divide seus trabalhos em três ações, a saber: 1- pré-análise; 2- descrição analítica; e 3- interpretação referencial. Na préanálise, organizam-se os dados teóricos colhidos conforme os objetivos, questão a investigar e literatura de suporte; na descrição analítica, o material é cuidadosamente desmembrado conforme o norte da pesquisa e categorizado em grupos codificados; e na descrição analítica, aprofundam-se as análises utilizando a literatura selecionada para tratar os resultados em prol do enriquecimento do estudo (BARDIN, 2016).

Sendo assim, a sessão seguinte, referente aos "Resultados e discussões" foi organizada em dois blocos, a saber: a- Relatos do diário de campo e; b- Elucidação das evidências.

\section{RESULTADOS E DISCUSSÕES}

\subsection{Relatos do diário de campo}

\subsubsection{Episódio 1, de 11 de maio de 2016: Dançarino da Anitta}

Após a realização da chamada, os(as) estudantes passaram a realizar atividades livres pela quadra em pequenos grupos ou sozinhos. Um dos estudantes, J.V., passou a dançar e 
coreografar uma de suas músicas preferidas da cantora Anitta, "Show das Poderosas". Seu colega G.P. passou a persegui-lo para dar-lhe socos e pontapés. J.V. corria, e toda vez que tomava distância o suficiente rapidamente retornava para seu ritual de canto e encenação. G.P., de longe, respondia: "Menininha, você é viadinho, para de fazer essas coisas". O professor parecia não ouvir, talvez em função da gritaria promovida pela turma, ou, se ouviu, apenas ignorou a ocorrência. J.V. não se importou com a fala de seu colega, colocando as mãos na cintura e fazendo uma expressão facial de desdém a cada vez que recebia a desaprovação de G.P.

Após G.P. desistir de sua perseguição em função do cansaço, aproximei-me de J.V. para conversar um pouco mais sobre suas habilidades em dança.

\author{
Pesquisador: Você gosta de dançar? \\ J.V.: Sim, gosto muito, eu danço lá perto de casa. \\ Pesquisador: Ah é? Nossa, que legal! E você gosta de qual cantora? \\ J.V.: Da Anitta. Quando crescer quero ser que nem ela! \\ Pesquisador: Ah, muito legal, então continue dançando que você vai conseguir \\ sim! Parabéns, você dança muito bem!
}

Nesse momento, três meninas estudantes se aproximaram para dizer que também gostavam de cantar e dançar. J.V. voltou a cantar e dançar "Show das Poderosas", ocasião em que as meninas passaram a imitá-lo.

\title{
3.1.2 Episódio 2, de 15 de junho de 2016: A Cinderela perdeu seu sapatinho de cristal
}

O professor organizou a turma em uma fileira de meninos e outra de meninas. Após essa divisão, ele ordenou que o(a) primeiro(a) estudante de cada fileira passasse por debaixo das pernas dos colegas, que formaram uma espécie de túnel. Um(a) um(a), passaram a realizar a atividade, rindo, gritando e se divertindo com a proposta.

Os membros dos túneis adoravam dificultar a travessia dos(as) colegas através da diminuição do espaço pelo fechamento das pernas. No grupo de meninos, quando J.V. encontrava-se como protagonista, um de seus pés ficou preso entre as pernas de dois colegas. J.V. começou a gritar e a forçar a soltura do pé, ocasião em que seu tênis acabou ficando pelo caminho no momento de se desvencilhar. Ao chegar ao final do túnel, levantou aos berros: "Ah, a Cinderela perdeu seu sapatinho de cristal! A Cinderela perdeu seu sapatinho de cristal", correndo através de saltos, com os cotovelos flexionados e os punhos frouxos em busca de seu calçado que, a essa altura, já havia sido jogado longe pelos colegas.

Seu colega F.G. olhou com um misto de dúvida e estranhamento para J.V., dizendo: "A Cinderela é menina. Você não pode ser a Cinderela". J.V., no entanto, apenas colocou os braços na cintura, encarou o amigo e fez sua expressão de desdém. F.G. cochichou com seus colegas, mas rapidamente o foco do grupo retornou à atividade e à tentativa de prender os colegas que sob eles passavam.

\subsubsection{Episódio 3, de 13 de julho de 2016: Espaços (im)próprios}

Após o professor terminar a chamada, a turma passou a correr livremente pela quadra e a brincar com os materiais dispostos: uma bola de futebol, uma de basquete, três petecas e 
uma corda. As meninas se reuniram com as petecas e corda enquanto os meninos utilizaram as bolas para chutar e arremessá-las contra os colegas. O estudante J.V. foi o único que se manteve alheio a essa divisão, correndo sozinho enquanto gritava com medo de ser atingido pelas bolas e observava as garotas pulando corda e brincando com as petecas. Em determinado momento, tentou inserir-se nas atividades de corda, mas foi repreendido por uma de suas colegas, que disse que aquele era o espaço das meninas. J.V. fez sua expressão de deboche, afastando-se dali e novamente passando a correr sem rumo pela quadra e gritando com medo de ser atingido.

\subsubsection{Episódio 4, de 20 de julho de 2016: "Ninguém torce pra você!"}

Após o professor terminar a chamada, propôs à turma a realização de um percurso de atividades que consistia em saltar cones, rastejar de uma linha da quadra à outra (seis metros), arremessar um saco de areia à frente, rolar sobre o colchonete e chutar uma bola ao gol. Para tanto, foi determinando a vez de cada aluno(a) de modo que sempre houvesse dois discentes ao mesmo tempo no circuito disputando entre si.

A quinta disputa foi marcada entre os alunos J.V. e F.B. Durante a realização desse embate, a turma formou coro em apoio a F.B., fato que ocorreu apenas naquele momento, não sendo evidenciado até então. F.B. conseguiu, de fato, terminar antes de J.V., para alegria e euforia da turma, principalmente meninas, que pularam alegres ao contemplarem a vitória do colega. J.V., a retornar para o conglomerado de alunos(as), ouviu de seu colega G.P.: "Ninguém torce pra você!", que ainda lhe mostrou a língua. J.V. colocou os braços na cintura, fez sua expressão de deboche e acenou com o braço, em um gestual interpretativo de não se importar com aquilo.

\subsection{Elucidação das evidências}

Historicamente, as aulas de Educação Física Escolar encontram-se ancoradas na reprodução de um modelo hegemônico, sexista, generificado e excludente (ALTMANN, 2002; ALTMANN, 2015; BRITO; LEITE, 2017; DORNELLES; DAL'IGNA, 2015; FRANCO, 2016; PRADO; RIBEIRO, 2016; SOUSA; ALTMANN, 1999). Gênero, presente nesta esfera enquanto mantenedor social de hierarquias, atua como um importante dispositivo não apenas regulador das sexualidades, mas também do direcionamento das práticas pedagógicas escolares (PEREIRA; FERNANDES FILHO, 2009).

Nas quatro cenas que trazemos para análise, temos como protagonista o estudante J.V., um aluno menino, magro, de cor parda, olhos escuros, cabelo raspado e estatura comum para a idade que, embora cercado de discursos coercitivos dos(as) colegas, principalmente dos garotos, revela não se importar com perseguições ou ainda com os termos pejorativos que Ihe recaem. $\mathrm{O}$ garoto transparece identificações e performances alternativas àquela esperada a sujeitos que se identificam como meninos/homens, não correspondendo às expectativas da turma, o que desencadeia condutas aqui elencadas como homofóbicas para tentar redirecionálo aos enquadramentos normatizadores. A homofobia é um importante mecanismo que atua para manter e sustentar o discurso heterocompulsório de identidades sociais e sexuais, policiando as corporalidades e sobretudo as expressões de gênero (LOURO, 1998), sendo, portanto, "[..] uma prática e um valor que atravessa e organiza as relações sociais, distribui poder e regula comportamentos, inclusive no espaço escolar" (BENTO, 2011, p. 556). 
Aqui, podemos indicar o ambiente da Educação Física Escolar como heterossexista e homofóbico, à luz de Junqueira (2012), que compreende tais atributos como "[...] manifestações de sexismo, não raro associadas a diversos regimes e arsenais normativos, normalizadores e estruturantes de corpos, sujeitos, identidades, hierarquias e instituições, tais como o classismo, o racismo, a xenofobia" (JUNQUEIRA, 2012, p. 67).

Como podemos perceber nos quatro episódios, faz-se presente um discurso sexopolítico ${ }^{7}$ de coerção que vigia, assegura e/ou desvalia meninos e meninas através de gestos, da linguagem, das perseguições e da demarcação de territórios fixos e intransitáveis. Em outras palavras, existe a naturalização, internalização e incorporação das normas sexuais e de gênero, "[...] através de um sistema educativo e social que castigava todas as formas de dissidência com a ameaça, a intimidação, o castigo, e a morte" (PRECIADO, 2013, p. 98).

Esse tipo de ambiente solidifica e estimula a pedagogia do insulto com o intuito de ridicularizar e/ou inferiorizar corpos em descompasso com a heteronorma, contribuindo para manter dominações, ajustes e normatizações heterorregulados. Ainda, desponta subsequente a pedagogia do armário, marcada por tensões entre revelação e invisibilização das sexualidades desviantes, resultando no ensinamento, circulação e vivência de preceitos escolares heteronormalizadores.

Percebe-se, também, a forte presença de uma política heteroterrorista neste espaço analisado, conceito este que tomamos à luz de Berenice Bento (2011). A demarcação de atividades e espaços que limitam masculinidades e feminilidades, bem como a repressão a todos(as) aqueles(as) que tentam transpor essas fronteiras disparam imediatamente um enunciado - efeitos da linguagem reiterada - de cunho discricionário, conforme as normas de gênero.

As reiterações que produzem os gêneros e a heterossexualidade são marcadas por um terrorismo contínuo. Há um heteroterrorismo a cada enunciado que incentiva ou inibe comportamentos, a cada insulto ou piada homofóbica. Se um menino gosta de brincar de boneca, os heteroterroristas afirmarão: 'Pare com isso! Isso não é coisa de menino!'. A cada reiteração do/a pai/mãe ou professor/a, a cada 'menino não chora!', 'comporta-se como menina!', 'isso é coisa de bicha!', a subjetividade daquele que é o objeto dessas reiterações é minada (BENTO, 2011, p. 552).

Sob essa perspectiva, o ato de dançar revela-se como instrumento de desqualificação, ou ainda inferiorização da performance de gênero tida como dissidente à norma, uma vez que a ela conferem-se elementos feminizantes, destacando um tratamento diferenciado que consubstancia com a legitimação e naturalização de hierarquias entre os gêneros (LOURO, 2010). Ainda, brincar de corda não lhe é apropriado, uma vez que essa atividade "é para meninas", ou seja, caso J.V. queira praticar algum exercício, deve se inserir no universo dos meninos, das masculinidades, da disputa, da agressividade, pois naquele imaginário é bem circunscrito às atividades segregadas entre os sexos, amplamente disseminadas conforme dados de cunho biológico, fisiológico e cultural que sustentam essas premissas hierarquizantes e desiguais (GOELLNER, 2007).

J.V., no entanto, demonstra ser demasiadamente seguro para performatizar sua corporalidade sem importar-se com a resposta dos(as) demais. Percebe-se, todavia, um

7 A sexopolítica pode ser compreendida como uma das vertentes de dominação da biopolítica capitalista contemporânea, onde o sexo, os órgãos, práticas e identidades sexuais "normais" e desviantes, bem como os códigos de masculinidade e feminilidade atuam nas formulações de poder, "[...] fazendo dos discursos sobre o sexo e das tecnologias de normalização das identidades sexuais um agente de controle da vida" (PRECIADO, 2011, p. 11). 
processo de exclusão primária desse aluno, uma vez que, constantemente policiado pelos(a) demais, o garoto torna-se indigno de pertencimento aos grupos daquela turma por exteriorizar aspectos que o desqualificam nesse jogo de reconhecimentos, sendo, ainda, azarado ao competir contra um de seus colegas sob o enunciado de "Ninguém torce pra você!".

Ao perder o sapato, realiza uma espécie de paródia da Cinderela, uma das princesas clássicas da Disney e muito conhecida no universo das crianças. Sua transição entre as fronteiras revela uma performance de gênero que é bem delineada: apropriar-se de uma identificação feminina requer, portanto, a transpiração de determinados elementos que atuam como marcadores, sobretudo como qualificadores. Correr de uma maneira diferente estaria, para ele, convergindo com o que se esperava de uma princesa correndo, muito próximo à cena do filme em que a protagonista foge do príncipe de volta ao lar após o tempo do feitiço que a embelezava expirar.

Conforme Butler (2015), a paródia de gênero, exemplificada através da performance artística de uma drag queen, desmonta a ideia de que um gênero decorra do sexo, assim como da coerência entre identidade e performance de gênero. Essa noção contesta qualquer identidade original ou primária ao explicitar que um sujeito de um sexo (nascido com um pênis, por exemplo) possa realizar uma performance de gênero (feminino, conforme o exemplo de J.V.), denunciando como masculino e feminino são construções culturais de uma suposta coerência heterossexual: "[...] vemos sexo e o gênero desnaturalizados por meio de uma performance que confessa sua distinção e dramatiza o mecanismo cultural da sua unidade fabricada" (BUTLER, 2015, p. 238).

Por transitar e transgredir as fronteiras, J.V. configura um status de dissidência entre sexo e gênero, desafiando, confundindo e despertando em seus colegas estranhamentos e dúvidas acerca de sua identificação por suas performances e paródias. Isso abre margem para uma ressignificação de conceitos através do questionamento das verdades absolutas, configurando um movimento queer, que almeja problematizar as normas heterocentradas e questionar identificações de gênero binárias, possibilitando, assim, a emersão de discussões fluidas sobre identidades, expressões e performatizações de gênero, sem, no entanto, estabelecer novas categorias de identificação (MISKOLCI, 2009; 2012; LOURO, 2013).

Desta forma, J.V. precisa, sozinho e em condição de precariedade naquele contexto escolar, resistir isoladamente aos preceitos heteronormativos que são aplicados sobre si e seus colegas. A noção de precariedade designa a condição politicamente induzida em que alguns corpos se encontram mais suscetíveis e expostos à injúria, violência e vulnerabilidade. Corpos que não performatizam seu gênero de maneira inteligível, coerente com um quadro binário, encontram-se, muitas vezes, em condição alta de precariedade nos diferentes contextos sociais (BUTLER, 2016).

Isso ocorre aos que fogem da heteronorma, sinalizando a existências de hierarquias que classificam e interpretam sujeitos heterodissidentes enquanto seres miseráveis em dignidade e/ou possuidores de vidas/corpos menos importantes. Nos episódios que trazemos aqui, identificamos certo tipo de ameaça à J.V., através de violências simbólicas e físicas que denunciam o estado de corpo/vida precário do referido estudante enquanto menos valioso que dos demais. Conforme apontam Dornelles e Dal'Igna (2015, p. 1591), "[...] há muitas vidas na Educação Física Escolar, por exemplo, que ocupam o lugar da descontinuidade, da incoerência e da não humanidade". Por ser interpretado como estranho, perturbador e provocativo, ao 
garoto (re)nega-se o mesmo direito de participação e reconhecimento conferidos à turma de modo geral, uma vez que suas ações, gestos, linguagens e discursos convergem com masculinidades 8 ínfimas que só poderão amadurecer via absorção de elementos descometidos, imperiosos e diretivos que são declamados por seus colegas.

Para além de tais observações, convém trazer às discussões a postura do professor enquanto educador, ponto de referência dos(as) alunos(as) e responsável pelo tratamento das condutas do corpo discente. Nesta conjuntura, ele não se atenta para as ocorrências e insultos direcionados a J.V. Não intervir, sendo, portanto, omisso e conivente com tal prática, legitima os saberes heterorregulatórios e respalda esse tipo de ação, que acaba por naturalizar e cristalizar um discurso generificador, excludente e hierarquizado em múltiplas facetas (ALTMANN, 2015; BRITO, LEITE, 2017; DORNELLES; DAL'IGNA, 2015; FRANCO, 2016; JACO, ALTMANN, 2017; PRADO, RIBEIRO, 2016; SOUSA, ALTMANN, 1999), dentre as quais enfatizamos as relacionadas às normalizações das performances de gênero.

A cristalização desses preceitos pode resultar, por fim, na evasão das aulas de Educação Física e até da escola. Nota-se que a evasão é o produto final de uma série de acometimentos que, segundo Bento (2011), podem ser denominados enquanto processos de expulsão. A autora sugere que não existe por si só a evasão escolar, mas sim uma série de expulsões que são imputadas aos desviantes pouco a pouco até evoluírem ao fenômeno de exclusão. Ou seja, em decorrência das constantes violências orquestradas contra os "contaminadores" - compreendidos enquanto sujeitos subversivos e deslocadores de saberes, sentidos e normas até então intransigentes - e desviantes das práticas físicas tidas como naturais entre os sexos (GOELLNER, 2007), tais alunos(as) acabam por boicotar as aulas práticas com receio de sofrerem desaprovações ou ainda violações morais e físicas (SOUSA; ALTMANN, 1999). Em outras palavras, estão presentes em matéria/corpo, mas não participam ativamente das tarefas, ou quando tentam são constrangidos(as) e intimidados(as) pelos(as) colegas, o que denuncia um processo de exclusão primária que pode se estender - caso ainda não tenha se pulverizado - para as demais disciplinas e atividades escolares, diminuindo cada vez mais a participação, a vontade e a motivação de estar presente daquele(a) aluno(a), maturando, assim, o processo de evasão escolar.

Como já explicitado, a Educação Física é o componente curricular escolar que detém para si a peculiaridade de maior exposição dos corpos em ação, em que as performatizações de gênero estão postas em voga. Carregar tal particularidade não a eximiria de uma responsabilidade, aqui indicada como potência de desnaturalização do discurso histórico e biomédico sobre as práticas físicas entre os sexos, que recai justamente ao ator da docência, muitas vezes em momentos turbulentos, embaraçosos e labirínticos.

Pensar em enfrentamento das questões de gênero irrompe como uma grande oportunidade de problematizar, descontruir e desnaturalizar práticas generificadas, segregadoras e excludentes na Educação Física Escolar (DORNELLES; DAL'IGNA, 2015). Desta forma, refletir sobre currículos ou pedagogias com foco destinado ao reconhecimento

8 Ainda que a teorização da masculinidade hegemônica, da socióloga australiana Raewyn Connell tenha sido a base teórica central das principais publicações sobre a temática nas pesquisas em Educação Física, conforme Brito e Leite (2017) apontaram em levantamento da produção acadêmica, pensamos a categoria masculinidade, neste artigo, em consonância com as perspectivas pós-estruturalistas. A noção que nos aproximamos, proposta por estes autores, parte da afirmação de que disputas se travam para estabelecer o que é normal/ anormal, legitimado/deslegitimado entre repetições/deslocamentos de sentidos da masculinidade como performatização de gênero. Mesmo as estabilizações do masculino, que se aproximam da norma, são tidas como provisórias, pois estão sempre em indagação pelas contingências dos diferentes contextos. 
e produção das diferenças, entendendo processos instáveis e de precariedade de gênero e sexualidades, torna-se uma necessidade emergente e urgente, não apenas para delatar exclusões e constantes violências de ordem simbólica e física ao qual sujeitos queer ou heterodissidentes enfrentam, mas também para desnaturalizar, descristalizar e desconstruir maquinismos que certificam tais validades binárias de gênero e sexualidades (LOURO, 2013).

\title{
4 CONSIDERAÇÕES FINAIS
}

Este estudo buscou investigar as relações de gênero e sexualidades em quatro episódios na Educação Física Escolar, protagonizados por um menino estudante que não se enquadrava nas normas binárias de gênero, trazendo à tona manifestações desviantes dos padrões clássicos esperados para meninos e sua(s) masculinidade(s). A experienciação dessa corporalidade alternativa no espaço escolar desencadeou condutas de estranhamento, exclusão e repulsa, enquadrando o menino estudante na condição de desvio, por sua performance de gênero dissonante à norma.

Para além disso, a (não) atitude do docente responsável colaborou para legitimar, naturalizar e favorecer a cristalização de preceitos heteronormativos já arraigados nos discursos controladores das sexualidades, permitindo assim o estabelecimento e manutenção de hierarquias identitárias entre os(as) próprios(as) alunos(as). Não se atentar para tais ocorrências, além de grave, vai na contramão da profissão docente, principalmente no que tange ao educar pensamentos e opiniões em uma sociedade crítica, democrática e inclusiva.

Convém ressaltar um consenso na existência de lacunas na formação de professores de Educação Física, dentre elas a ausência de discussões sobre gênero e sexualidades, o que contribui para uma formação menos crítica sobre esses preceitos, naturalizando discursos biologicistas, sexistas e heteronormativos (ALTMANN, 2002; ALTMANN, 2015; FRANCO, 2016; MARIANO; ALTMANN, 2016; PRADO; RIBEIRO, 2016; SOUSA; ALTMANN, 1999).

Defendemos, portanto, a implementação de currículos e pedagogias que direcionem seus olhares para as diferenças, em particular nas questões de gênero e sexualidade, objetivando desnaturalizar, descristalizar e desconstruir certificações que ratificam condutas segregacionistas nos contextos escolares.

\begin{abstract}
Eles defendem o poder de educar os filhos dentro da norma sexual e de gênero, como se fossem supostamente heterossexuais. Eles desfilam para conservar 0 direito de discriminar, castigar e corrigir qualquer forma de dissidência ou desvio, mas também para lembrar aos pais dos filhos não-heterossexuais que o seu dever é ter vergonha deles, rejeitá-los e corrigi-los. Nós defendemos o direito das crianças a não serem educadas exclusivamente como força de trabalho e de reprodução. Defendemos o direito das crianças e adolescentes a não serem considerados futuros produtores de esperma e futuros úteros. Defendemos 0 direito das crianças e dos adolescentes a serem subjetividades políticas que não se reduzem à identidade de gênero, sexo ou raça (PRECIADO, 2013, p. 99).
\end{abstract}

Assim, oportuniza-se o reconhecimento das inúmeras performatizações de gênero, sexo e desejo, além de potencializar as discussões problematizadoras sobre normas e convenções já tão legitimadas nas práticas da Educação Física Escolar. 


\section{REFERÊNCIAS}

ALTMANN, Helena. Exclusão nos esportes sob um enfoque de gênero. Motus Corporis, v. 9, n. 1, p. 9-20, 2002.

ALTMANN, Helena. Educação física escolar: relações de gênero em jogo. São Paulo, Cortez, 2015.

ARIĖS, Philippe. História social da criança e da família. Rio de Janeiro: Guanabara, 1981.

BARDIN, Laurence. Análise de conteúdo. Ed. rev. ampl. São Paulo: Edições 70, 2016.

BENTO, Berenice. Na escola se aprende que a diferença faz a diferença. Revista Estudos Feministas. v. 19, n. 2, p. 548-559, maio/ago. 2011.

BRITO, Leandro Teofilo de; LEITE, Miriam Soares. Sobre masculinidades na Educação Física escolar: questões teóricas, horizontes políticos. Práxis Educativa, v. 12, n. 2, p. 481-500, maio/ ago. 2017.

BRITO, Leandro Teofilo de; SANTOS, Mônica Pereira dos. Sexualidade e inclusão no espaço escolar: um debate com base na perspectiva omnilética. Revista latino-americana de Geografia e Gênero, v. 9, n.1, p. 51-71, 2018.

BUTLER, Judith. Problemas de gênero: feminismo e subversão da identidade. 8. ed. Rio de Janeiro, Civilização Brasileira, 2015. (Col. Sujeito \& História).

BUTLER, Judith. Corpos que ainda importam. In: COLLING, Leandro. (Org.). Dissidências sexuais e de gênero. Salvador: EDUFBA, 2016. p. 19-42.

COUTO JUNIOR, Dilton Ribeiro; POCAHY, Fernando; OSWALD, Maria Luiza. Crianças e infâncias (im)possíveis na escola: dissidências em debate. Revista Periódicus, v. 1, n. 9, p. $55-74,2018$.

DEMO, Pedro. Pesquisa e informação qualitativa: aportes metodológicos. 5. ed. Campinas: Papirus, 2012.

DORNELLES, Priscila Gomes; DAL'IGNA, Maria Cláudia. Gênero, sexualidade e idade: tramas heteronormativas nas práticas pedagógicas da educação física escolar. Educação e Pesquisa, v. 41, p. 1585-1599, dez. 2015.

FELIPE, Jane. Estudos Culturais, Gênero e Infância: Limites e Possibilidades de uma Metodologia em Construção. Textura, v. 11, n. 19-20, p. 4-13, 2009.

FRANCO, Neil. A Educação Física como território de demarcação dos gêneros possíveis: vivências escolares de pessoas travestis, transexuais e transgêneros. Motrivivência, v. 28, n. 47, p. 47-66, maio 2016.

GOELLNER, Silvana Vilodre. Feminismos, mulheres e esportes: questões epistemológicas sobre o fazer historiográfico. Movimento, v. 13, n. 2, p. 171-196, maio/ago. 2007.

GOELLNER, Silvana Vilodre. A educação dos corpos, dos gêneros e das sexualidades e o reconhecimento da diversidade. Cadernos de Formação RBCE, p. 71-83, mar. 2010. 
JACO, Juliana Fagundes; ALTMANN, Helena. Significados e expectativas de gênero: olhares sobre a participação nas aulas de educação física. Revista Educação em Foco, v. 22, n. 1, p. 1-26, jun. 2017.

JUNQUEIRA, Rogério Diniz. A pedagogia do armário: heterossexismo e vigilância de gênero no cotidiano escolar. Revista Educação Online, n.10, p. 64-83, 2012.

LOURO, Guacira Lopes. Segredos e Mentiras do Currículo: sexualidade e gênero nas práticas escolares. In: SILVA, Luiz. A Escola Cidadã no Contexto da Educação Globalizada. Petrópolis: Vozes, 1998. p. 33-47.

LOURO, Guacira Lopes. Pedagogias da sexualidade. In: LOURO, G. L. (Orgs.). 0 corpo educado: pedagogias da sexualidade. 3. ed. Belo Horizonte: Autêntica, 2010. p. 7-35.

LOURO, Guacira Lopes. Um corpo estranho: Ensaios sobre sexualidade e teoria queer. 2. ed. Belo Horizonte: Autêntica Editora, 2013.

MARIANO, Marina; ALTMANN, Helena. Educação Física na Educação Infantil: educando crianças ou meninos e meninas? Cadernos Pagu, n. 46, p. 411-438, abr. 2016.

MISKOLCI, Richard. A Teoria Queer e a Sociologia: o desafio de uma analítica da normalização. Sociologias, v. 21, p. 150-182, jan./jun. 2009.

MISKOLCI, Richard. Teoria Queer: um aprendizado pelas diferenças. 2. ed. Belo Horizonte: Universidade Federal de Ouro Preto, 2012.

PEREIRA, Erik Giuseppe B.; FERNANDES FILHO, José. A construção das masculinidades: os discursos e as imagens na educação física infantil. InterSciencePlace, v. 1, n. 8, jul./ago. 2009.

PRADO, Vagner Matias do; RIBEIRO, Arilda Ines Miranda. Escola, homossexualidades e homofobia: rememorando experiências na Educação Física escolar. Revista Reflexão e Ação, v. 24, n. 1, p. 97-114, jan./abr. 2016.

PRECIADO, Beatriz. Multidões queer: notas para uma política dos "anormais". Revista Estudos Feministas, v. 19, n. 1, p. 11-20, abr. 2011.

PRECIADO, Beatriz. Quem defende a criança queer? Tradução Fernanda Ferreira Marcondes Nogueira. Jangada: crítica, literatura, artes, n. 1, p. 96-99, ago. 2013.

REIS, Cristina d'Ávila; PARAISO, Marlucy Alves. Normas de gênero em um currículo escolar: a produção dicotômica de corpos e posições de sujeito meninos-alunos. Revista Estudos Feministas, v. 22, n. 1, p. 237-256, jan./abr. 2014.

RICHARDSON, Roberto Jarry. Pesquisa social: métodos e técnicas. 3. ed. São Paulo: Atlas, 2008.

SOUSA, Eustáquia Salvadora de; ALTMANN, Helena. Meninos e meninas: expectativas corporais e implicações na educação física escolar. Cadernos CEDES, v. 19, n. 48, p. 52-68, ago. 1999.

TRIVIÑOS, Augusto Nibaldo Silva. Introdução à pesquisa em ciências sociais: a pesquisa qualitativa em educação. O positivismo; a fenomenologia; o marxismo. São Paulo: Atlas, 2015.

WARNER, Michael. Fear of a queer planet: queer politics and social theory. Minnesota: Minnesota Press, 1991. 
